\title{
Sequential Inhalational Tobramycin- Colistin-Combination in CF-Patients with Chronic P. Aeruginosa Colonization - an Observational Study
}

\author{
Joachim Riethmüllera Gloria Herrmann ${ }^{a} \quad$ Ute Graepler-Mainka ${ }^{a}$ Dorothea Hellwig ${ }^{b}$ \\ Hans-Eberhard Heuerc Susanne Heyder ${ }^{\mathrm{a}}$ Holger Köster ${ }^{\mathrm{d}}$ Birte Kinder \\ Kristina Kröger ${ }^{f}$ Klaus Paulg Krystyna Poplawska ${ }^{h}$ Volker O. Melichari \\ Christina Smacznyj Uwe Melliesk \\ aDepartment of Pediatrics, Comprehensive Cystic Fibrosis Center, University Children`s Hospital \\ Tuebingen, Tuebingen, bUniversity Children`s Hospital Freiburg, Freiburg, 'CF-Ambulance Hamburg, \\ Hamburg, ${ }^{d}$ Klinikum Oldenburg, Oldenburg, e Dietrich Bonhoeffer Klinikum Neubrandenburg, \\ Neubrandenburg, 'Luisenhospital Aachen, Aachen, 9CF-Ambulance Berlin, Berlin, hUniversity Children`s \\ Hospital Mainz, Mainz, iUniversity Children`s Hospital Erlangen, Erlangen, iUniversity Hospital \\ Frankfurt, Frankfurt, kUniversity Children`s Hospital Essen, Essen, Germany
}

\section{Key Words}

Cystic Fibrosis • Lung infection • P. aeruginosa • Inhaled tobramycin and colistin

\begin{abstract}
Background/Aims: In cystic fibrosis (CF), chronic microbial lung infections are difficult to treat and cause morbidity and increased mortality. Methods: In a multicentre, open-label, exploratory, non-interventional study, inhaled tobramycin (300 mg twice daily) and colistin (1 million I.U. twice daily) were sequentially combined with the aim to investigate the effect on 41 CF patients with chronic $P$. aeruginosa infections for six months (mean age $24 \pm 10.8 \mathrm{y}$ ). Results: Six patients had adverse events that were assessed as being related to treatment. Mucus production and coughing both decreased in $39 \%$, whereas FEV ${ }_{1}$ absolute and relative to baseline increased by $4.9 \%$ and $9.1 \%$, respectively $(p=0.004)$ in 29 patients, who were definitely treated sequentially. Efficacy of the therapy was rated 'excellent' or 'good' by the physicians in $80.5 \%$ of the patients. Conclusions: The results indicate that treatment with inhaled antibiotics, sequentially combined, was very well tolerated by most patients and may have a beneficial effect, even if transitory on lung function and respiratory symptoms.
\end{abstract}




\section{Cellular Physiology Cell Physiol Biochem 2016;39:1141-1151

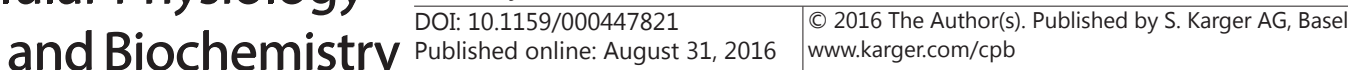 \\ Riethmüller et al.: Sequential Inhaled Antibiotics in CF}

\section{Introduction}

The genetic disorder cystic fibrosis (CF) caused by mutations in the gene CF Transmembrane Conductance Regulator (CFTR) [1, 2], affects approximately 80,000 Caucasian individuals in Europe and North America. In airways of CF-patients chronic microbial infection and inflammation is provoked [3] leading to excessive lung tissue destruction which is the most important cause of morbidity and mortality in these patients [4].

Inhaled tobramycin and/or colistin monotherapy are used as long-term medications for the treatment of Pseudomonas aeruginosa infection in patients with CF [3, 5, 6]. Inhaled antibiotic therapy, shortly initiated after colonization of the airways by $P$. aeruginosa, has led to high eradication rates [3]. However, once P. aeruginosa lung infections become chronic, antibiotics do not eradicate the pathogens in the CF airways due to bacterial biofilm formation [7], development of mutator strains [8] and drug adsorption to sputum components [9]. In clinical practice, several inhaled and systemic antibiotics are combined to treat CF-associated lung infections at this stage. The tolerability and efficacy of these combinations have not yet been systematically investigated [10]. If chronic $P$. aeruginosa infection is persistent and mucoid P. aeruginosa strains are present, systemic antibiotics, e.g. ciprofloxacin, clarithromycin, fosfomycin or azithromycin, are used as an add-on therapy to inhaled tobramycin or colistin monotherapy [11]. Recently, a combination of inhaled antibiotics, i.e. colistin and tobramycin, was studied in a pilot study [12].

Increasingly, sequential therapy of inhaled tobramycin followed by inhalation of either colistin or aztreonam during the off cycle of tobramycin, is occurring among CF patients.

Here we report on the feasibility, safety and efficacy of an open-labelled, noninterventional study of inhaled tobramycin and colistin sequential therapy in $41 \mathrm{CF}$ patients treated for 6 months.

\section{Materials and Methods}

\section{Study design and patients}

Pediatric and adult patients with CF, enrolled in twelve Cystic Fibrosis Centers in Germany (Tuebingen, $\mathrm{n}=7$; Stuttgart, $\mathrm{n}=3$; Freiburg, $\mathrm{n}=8$; Hamburg, $\mathrm{n}=5$; Oldenburg, $\mathrm{n}=5$; Neubrandenburg, $\mathrm{n}=1$; Aachen, $\mathrm{n}=2$; Berlin, $\mathrm{n}=1$; Mainz, $\mathrm{n}=5$; Erlangen, $\mathrm{n}=2$; Frankfurt, $\mathrm{n}=1$ and Essen, $\mathrm{n}=1$ ), were eligible to be included in the study: 1. diagnosis of cystic fibrosis was verified, 2. 6 years or older, 3. chronic P. aeruginosa lung infection ( $\geq 6$ months) at screening, 4. susceptibility of P. aeruginosa to tobramycin and/or colistin, 5 . normal kidney function and normal hearing ability, 7. a treatment escalation due to aggravated symptoms or deterioration of lung function was present. Patients were not included in case of: 1. hypersensitivity to colistin, polymyxin B, or aminoglycosides were present, 2. Myasthenia gravis was present and 3. were pregnant or breast feeding.

Criteria for termination of treatment were not prospectively defined and protocol violations were not determined because of the non-interventional character of the study. The decision for a therapy with inhaled tobramycin and colistin had to be made by the physician prior to the inclusion of a patient into the study, but after inclusion some patients or patient's parents decided not to be treated analogue the study outline.

All patients were analyzed for safety and efficacy. Efficacy analyses were also performed in a subgroup, which was defined as patients who had combined tobramycin/colistin treatment and had no acute pulmonary exacerbations at the beginning or at the end of the observational period. Pulmonary exacerbations were defined as two or more of the following criteria: change in sputum volume, color or increased cough or increased malaise, fatigue, lethargy or anorexia, weight loss or decrease in pulmonary function $\left(\mathrm{FEV}_{1}\right)$ by $10 \%$ or more, or radiographic changes or increased dyspnoea. In addition to the study protocol, data on acute pulmonary exacerbations were collected.

In the case report forms all patients were anonymized by means of a patient number to be identified via the patient identification list only. The patient identification list was kept exclusively with the investigating physicians in the investigator site file. Monitoring for this study was provided by the sponsor. 


\section{Cellular Physiology Cell Physiol Biochem 2016;39:1141-1151 \begin{tabular}{l|l|l|} 
DOI: 10.1159/000447821 2016 The Author(s). Published by S. Karger AG, Basel & $\begin{array}{l}\text { (c) 2016 Tiochemistry } \\
\text { www.karger.com/cpb }\end{array}$
\end{tabular} \\ Riethmüller et al.: Sequential Inhaled Antibiotics in CF}

As requested by law, the study was reported to the Federal Institute for Drugs and Medical Devices (Bundesinstitut für Arzneimittel und Medizinprodukte, BfArM). The study was performed in accordance with the Declaration of Helsinki and under the regulations of Good Clinical Practice. The study was approved by the ethics committee at the medical faculty of the Eberhard-Karls-University and the University Hospital Tübingen and written informed consent was obtained from all patients.

\section{Study Procedures}

Patients have been foreseen to receive $300 \mathrm{mg}$ of tobramycin $\left(\right.$ Bramitob $^{\circledR}$ ) inhaled twice daily (morning and evening, 12-hour interval recommended) for 28 days followed by Colistin (1 million I.U.) twice daily for 28 days, given during the therapy free intervals of tobramycin treatment ('off cycles'), over an overall period of 6 months, because of known chronic Pseudomonas colonization. Both drugs were inhaled via individual used inhalator devices (PARI GmbH, Starnberg, Germany). Patients were screened prior to treatment and treated as outpatients for 6 months. Details on previous therapies for P. aeruginosa infection within the 6 months prior to the first visit were documented. Concomitant medications for the treatment of diseases/ medical conditions other than chronic P. aeruginosa infection were not documented. Data were documented at three visits: first visit at baseline, second visit after $84 \pm 14$ days and the final visit after $180 \pm 28$ days analogous to common visits at sites.

Study-related tests and examinations included the assessment of medical history data, previous treatment regimens, reasons for change from monotherapy to sequential therapy, pulmonary function testing, Pseudomonas antibiogram, respiratory symptoms, assessment of compliance by questionnaire and adverse events at all visits. At the final visit, physicians and patients evaluated the tolerability of the combination therapy on a 5 -point scale $(1=$ very good, $2=$ good, $3=$ satisfactory, $4=$ insufficient, $5=$ not assessable).

Aged-matched efficacy measurements included assessment of lung function (forced vital capacity (FVC); forced expiratory volume in 1 second $\left(\mathrm{FEV}_{1}\right)$; maximal expiratory flow - $\mathrm{MEF}_{25}$ and $\left.\mathrm{MEF}_{25 / 75}\right)$ at each visit performed according ATS criteria, respiratory symptoms (e.g. cough, dyspnoea, sputum production) at each visit, frequency of $P$. aeruginosa, modified revised Cystic Fibrosis Questionnaire (CFQ-R) on 4-point scale and antibiograms in sputa testing the susceptibility of $P$. aeruginosa and/or other bacterial strains to tobramycin and colistin at each visit. Clinical laboratory investigations such as molecular determination or counting of Pseudomonas strains were not done due to the character of the study.

\section{Outcomes}

The primary endpoint was safety and tolerability which was assessed by numbering of side effects and adverse and serious adverse events.

Secondary endpoints (efficacy data) included the change in FVC, $\mathrm{FEV}_{1}, \mathrm{MEF}_{25}$ and $\mathrm{MEF}_{25-75}$ from baseline, change of pulmonary colonization, change of respiratory symptoms and assessment of efficacy and tolerability by physicians and patients at the final visit (after 6 months). The change of exacerbation and iv-treatment rates were retrospectively analyzed by questionnaire.

Finally, a post hoc analysis was done to evaluate the lung function trend observed in the 6 months prior to enrollment.

\section{Statistical Analysis}

The safety population included all patients treated with inhaled tobramycin or colistin for whom any data were documented. In case no entry on dosage was made, but other data were available, it was assumed that the patient received treatment for P. aeruginosa infection and the patient was included in the safety population. Patients with sequential therapy (tobramycin and colistin) and full available data were included in the subgroup.

The Student's t-test or Wilcoxon was applied where appropriate. Continuous variables were summarized by number, mean, standard deviation, minimum, lower quartile, median, upper quartile, and maximum. Categorical variables were presented in frequency distribution tables with number and percentage. Statistical analyses were performed using the statistical software package SAS (SAS Institute Inc.) version 9.1.3. The contract research organization Syneed Medidata GmbH, Konstanz, Germany was responsible for data management and monitoring. Adverse events were coded using theMedical Dictionary for Regulatory Activities (MedDRA) coding system (version 16.0). Medications were analyzed on the basis 


\section{Cellular Physiology Cell Physiol Biochem 2016;39:1141-1151 \begin{tabular}{ll|l} 
and & DOI.1159/000447821 & $\begin{array}{l}\text { O 2016 The Author(s). Published by S. Karger AG, Basel } \\
\text { www.karger.com/cpb }\end{array}$ \\
\cline { 2 - 3 }
\end{tabular} \\ Riethmüller et al.: Sequential Inhaled Antibiotics in CF}

of international nonproprietary names. Data analysis was done by Syneed Medidata GmbH.

No formal sample size determination was performed, because no prior systematic studies on the use of combined antibiotics for the treatment of CF-associated P. aeruginosa infection had been performed upon which to base effect calculations.

\section{Role of the funding source}

The funding sources had a role in study design, but not in data collection or analysis, report writing, or the decision to submit this paper for publication. All authors had full access to the data and participated in the decision to submit for publication.

\section{Results}

The prospective, multicentric, open label, observational study lasted for 24 months (4/2011 - 4/2013). A total of 41 patients were included in the study and in the safety population (Table 1). Protocol deviations were not analyzed due to the non-interventional character of the study. No patient was excluded from analyses of efficacy and safety. Efficacy data were available for 40 patients at the second visit and for 38 patients at the final visit. Thirty-six of all patients (88\%) received sequential therapy with tobramycin and colistin. Six of the patients $(14.6 \%)$ received an alternative treatment regimen with inhaled tobramycin

Table 1. Demographic characteristics, diagnosis of CF and respiratory tract infections

\begin{tabular}{|c|c|c|c|}
\hline \multicolumn{2}{|l|}{ Characteristic } & \multicolumn{2}{|c|}{ Total $(\mathrm{N}=41)$} \\
\hline \multirow[t]{2}{*}{ Age [years] } & $\mathrm{n}$ & \multicolumn{2}{|l|}{41} \\
\hline & Median (range) & \multicolumn{2}{|c|}{$24.0(6,50)$} \\
\hline Height $[\mathrm{cm}]$ & Median (range) & \multicolumn{2}{|c|}{$163.0(122,192)$} \\
\hline Weight $[\mathrm{kg}]$ & Median (range) & \multicolumn{2}{|c|}{$54.0(21,92)$} \\
\hline \multirow[t]{2}{*}{$\operatorname{Sex}[n(\%)]$} & Male & \multicolumn{2}{|c|}{$13(31.7)$} \\
\hline & Female & \multicolumn{2}{|c|}{$28(68.3)$} \\
\hline Duration of $\mathrm{CF}$, time since first diagnosis [years], $\mathrm{n}=40$ & Median (range) & \multicolumn{2}{|c|}{$18.5(2,42)$} \\
\hline Time since first detection of $P$. aeruginos $a$ in respiratory tract [years], $\mathrm{n}=39$ & Median (range) & \multicolumn{2}{|l|}{$7(1,28)$} \\
\hline $\begin{array}{l}\text { P. aeruginosa strains }[\mathrm{n}(\%)], \mathrm{n}=40 \\
\text { Mucoid } P \text {, aeruginosa }[\mathrm{n}(\%)], \mathrm{n}=18 \text { of } 40\end{array}$ & & \multicolumn{2}{|l|}{$19(30.2)$} \\
\hline \multirow[t]{6}{*}{ Time since latest detection of $P$. aeruginosa in respiratory tract [n (\%)] } & $<1$ months & 13 & $(31.7)$ \\
\hline & $1-2$ months & 8 & $(19.5)$ \\
\hline & 3-4 months & 10 & $(24.4)$ \\
\hline & $5-6$ months & 1 & $(2.4)$ \\
\hline & $>6$ months & 3 & $(7.3)$ \\
\hline & Missing data & 6 & $(14.6)$ \\
\hline \multirow[t]{2}{*}{ Detection of additional germs within the last 3 months [n (\%)] } & No & 4 & $(9.8)$ \\
\hline & Yes & 37 & $(90.2)$ \\
\hline \multirow[t]{6}{*}{ Kind of detected germ } & Staphylococcus & 22 & $(53.7)$ \\
\hline & Candida & 22 & $(53.7)$ \\
\hline & Aspergillus & 18 & $(43.9)$ \\
\hline & Haemophilus & 2 & $(4.9)$ \\
\hline & Streptococcus & 1 & $(2.4)$ \\
\hline & Other & 5 & $(12.2)$ \\
\hline \multicolumn{4}{|l|}{ Antibiotic treatment regimens } \\
\hline \multicolumn{2}{|l|}{ Tobramycin (300mg BID) and Colistin (1Mio BID) } & \multicolumn{2}{|c|}{$33(80.5)$} \\
\hline \multicolumn{2}{|l|}{ Tobramycin (150-300mg OD) and Colistin (1Mio BID) } & \multicolumn{2}{|c|}{$3(7.3)$} \\
\hline Tobramycin (150-300mg OD) or Colistin (1 Mio OD) & & \multicolumn{2}{|c|}{$3(7.3)$} \\
\hline \multicolumn{2}{|l|}{ Tobramycin (300mg BID) and Aztreonam (75mg trice) or } & \multicolumn{2}{|c|}{$2(5.0)$} \\
\hline
\end{tabular}




\section{Cellular Physiology Cell Physiol Biochem 2016;39:1141-1151 \begin{tabular}{ll|l} 
DOI: 10.1159/000447821 & O 2016 The Author(s). Published by S. Karger AG, Basel \\
www.karger.com/cpb
\end{tabular} \\ Riethmüller et al.: Sequential Inhaled Antibiotics in CF}

(150-300mg tobramycin once daily-OD), and three of them received colistin in the offcycles. Two patients (5\%) received sequential therapy with aztreonam and tobramycin or aztreonam and colistin, two patients $(5 \%)$ received monotherapy with tobramycin and one patient $(2 \%)$ received monotherapy with colistin. Previous monotherapy over a period of at least 6 months with inhaled tobramycin (on/off cycle) was reported for $36.6 \%(\mathrm{~N}=15)$ of the study population. Previous monotherapy with inhaled colistin was reported for $61.0 \%$ $(\mathrm{N}=25)$ of the study population. 17 patients $(41.5 \%)$ had previously been treated with intravenous (i.v.) antibiotics; 15 of these patients had received more than one i.v. antibiotic treatment in 6 months.

\section{Safety}

During the observation period, a total of 9 patients showed intolerance symptoms (including hoarseness, cough, and bronchial obstruction) after inhalation of tobramycin and/ or colistin. Four of these patients had shown intolerance reactions to inhaled tobramycin and/or colistin prior to the start of the study. The number of patients with intolerances were lower at the final visit $(\mathrm{N}=5)$, than at the second visit $(\mathrm{N}=9)$. Intolerance symptoms to inhaled tobramycin or sequential therapy including tobramycin were also reported as adverse events.

Eighteen adverse events were reported in 11 patients (26.8\%). Sixteen adverse events reported in 10 patients were assessed as being non-serious; two adverse events reported in 1 patient were assessed as being serious (hemoptysis, bronchial obstruction) and by the opinion of the investigator not related to the treatment. The most frequently reported adverse event was cough $(9.8 \%, \mathrm{~N}=4)$, followed by bronchial obstruction $(7.3 \%, \mathrm{~N}=3)$, dysphonia $(7.3 \%, \mathrm{~N}=3)$, oropharyngeal pain $(4.9 \%, \mathrm{~N}=2)$ all related to tobramycin treatment and viral infection $(4.9 \%, \mathrm{~N}=2)$. Haemoptysis, throat irritation, abdominal pain, and weight increase (in the opinion of an investigator declared as an $\mathrm{AE}$ ) each occurred in $2.4 \%(\mathrm{~N}=1)$ of all patients. A 30 year old female patient experienced bronchial obstruction after inhalation of tobramycin and severe haemoptysis. The therapy of the patient was changed to colistin monotherapy due to the bronchial obstruction.

\section{Efficacy Results}

\section{Treatment Compliance}

According to the assessment by the physicians at the end of the study (visit 3), treatment compliance was unchanged compared to the compliance of the previous therapy in the majority of the patients, i.e. in $73.2 \%(\mathrm{~N}=30)$. Compliance had improved in $14.6 \%(\mathrm{~N}=6)$ and decreased in $2.4 \%(\mathrm{~N}=1)$ of the study population. Data were missing for $9.8 \%(\mathrm{~N}=4)$.

\section{Changes from baseline in respiratory parameters}

According to the physicians' assessment, there were 22 patients with an improvement compared to baseline in at leastone of the assessed respiratory parameters (mucus production, coughing, and $\mathrm{FEV}_{1}$ ) at the final visit. Ten of these patients showed an improvement in all three assessed parameters. At the final visit, mucus production was unchanged in $51.2 \%$ (N $=21)$ and decreased in $39.0 \%(\mathrm{~N}=16)$ of all patients. Increased mucus production was not reported for any of the patients at the final visit. Data on mucus production were missing for $9.8 \%(\mathrm{~N}=4)$. Coughing had not changed in $46.3 \%(\mathrm{~N}=19)$, had decreased in $39.0 \%(\mathrm{~N}$ $=16)$, and had increased in $7.3 \%(\mathrm{~N}=3)$ of the study population at the final visit; data were missing for $7.3 \%(\mathrm{~N}=3)$.

\section{Determination of P. aeruginosa}

In 40 patients 44 non-mucoid and 19 mucoid $P$. aeruginosa strains could be found at study start, whereas in 36 patients a sputum analysis was possible after 6 months of treatment (Table 1). In these 36 patients the 37 non-mucoid strains were 12 times found to be resistant 


\section{Cellular Physiology Cell Physiol Biochem 2016;39:1141-1151 \begin{tabular}{ll|l} 
and BiOChemistry & $\begin{array}{l}\text { DOI: 10.1159/000447821 } \\
\text { Published online: August 31, } 2016\end{array}$ & $\begin{array}{l}\text { C } 2016 \text { The Author(s). Published by S. Karger AG, Basel } \\
\text { www.karger.com/cpb }\end{array}$ \\
\hline
\end{tabular} \\ Riethmüller et al.: Sequential Inhaled Antibiotics in CF}

Table 2. Lung function - time course and change from baseline to the end of the study (patients with complete data). ${ }^{\mathrm{a}}$ Change from baseline. FVC = forced vital capacity, $\mathrm{FEV}_{1}=$ forced expiratory volume in 1 second, $\mathrm{MEF}_{25}$ / $\mathrm{MEF}_{25-75}=$ maximal expiratory flow at $25 \%$ or between 25 and $75 \%$ of vital capacity. Means \pm SD are given

\begin{tabular}{|c|c|c|c|c|c|}
\hline Characteristic & & $\begin{array}{c}\text { Visit } 1 \\
\text { (Baseline) }\end{array}$ & $\begin{array}{c}\text { Visit } 2 \\
\text { (after } 3 \mathrm{~m} \text { ) }\end{array}$ & $\begin{array}{c}\text { Visit } 3 \\
\text { (after } 6 \mathrm{~m} \text { ) }\end{array}$ & $\mathrm{p}$-value \\
\hline FVC [\% predicted] & $\mathrm{N}=37$ & $79.5 \pm 21.8$ & $81.4 \pm 22.4$ & $82.4 \pm 23.5$ & 0.12 \\
\hline Absolute change ${ }^{a}$ & & & & $2.9 \pm 14.6$ & \\
\hline$\%$ (relative) changea & & & & $5.1 \pm 24.1$ & \\
\hline $\mathrm{FEV}_{1}[\%$ predicted] & $\mathrm{N}=38$ & $68.8 \pm 26.3$ & $70.4 \pm 27.2$ & $70.9 \pm 25.6$ & 0.14 \\
\hline Absolute change & & & & $2.1 \pm 11.5$ & \\
\hline$\%$ (relative) change & & & & $5.8 \pm 18.8$ & \\
\hline $\mathrm{MEF}_{25}[\%$ predicted] & $N=36$ & $33.9 \pm 26.9$ & $33.7 \pm 26.7$ & $32.4 \pm 25.6$ & 0.33 \\
\hline Absolute change & & & & $-1.5 \pm 20.1$ & \\
\hline$\%$ (relative) changea & & & & $21.3 \pm 112.4$ & \\
\hline $\mathrm{MEF}_{25-75}[\%$ predicted $]$ & $\mathrm{N}=34$ & $43.6 \pm 32.0$ & $47.5 \pm 34.8$ & $46.0 \pm 32.3$ & 0.21 \\
\hline Absolute change ${ }^{a}$ & & & & $2.4 \pm 17.6$ & \\
\hline$\%$ (relative) change & & & & $16.8 \pm 45.6$ & \\
\hline
\end{tabular}

against tobramycin and the 15 mucoid strains were not resistant against tobramycin and not against colistin. After 6 months of treatment the 32 non-mucoid strains ( $p=0.081$ ) were 14 times $(p=0.089)$ found to be resistant against tobramycin and the 16 mucoid $(p=0.17)$ strains were 2 times found resistant against tobramycin and non against colistin. A nondetection of $P$. aeruginosa was reported for $12.2 \%(\mathrm{~N}=5)$ of the study population at the final visit.

General clinical improvement

According to the physicians' assessment, a general clinical improvement was seen in in $56.1 \%(\mathrm{~N}=23)$ of all patients at the final visit. At visits 2 and 3, no general improvement was observed in $34.1 \%(\mathrm{~N}=14)$ of the study population. Data were missing for $9.8 \%(\mathrm{~N}=$ 4) at the final visit.

Changes in intravenous antibiotic therapy and exacerbation rates since baseline

The frequency of i.v. antibiotic therapy in 39 patients had changed from 37 treatments (mean $0.95 \pm 1.17) 6$ months before the start of the study to 27 treatments $(0.69 \pm 1.0)$ after 6 months of therapy (difference of $27 \%, p=0.02$ ). Exacerbation rates similarily decreased from mean $39(1.0 \pm 1.56) 6$ months before to $30(0.77 \pm 0.96)$ at the final visit (difference of $23 \%$; $\mathrm{p}=0.156$ ).

\section{Lung Function}

The results with regard to the lung function variables $\mathrm{FVC}, \mathrm{FEV}_{1}, \mathrm{MEF}_{25}$, and $\mathrm{MEF}_{25-75}$ are summarized in Table 2 for all patients having complete data available. The mean relative improvement in FVC \% predicted compared to baseline was $5.1 \%$ at the final visit $(p=0.12)$. The mean relative improvement in $\mathrm{FEV}_{1} \%$ predicted compared to baseline was $5.8 \%$ at the final visit $(\mathrm{p}=0.14)$. The inter-patient variability with regard to the $\mathrm{MEF}_{25}$ values and the change in $\mathrm{MEF}_{25}$ from baseline was high. The mean relative improvement in $\mathrm{MEF}_{25} \%$ predicted compared to baseline was $21.3 \pm 112.4 \%$ at the final visit, whereas the median relative improvement was $-1.5 \%(\mathrm{p}=0.33)$. The mean relative improvement in $\mathrm{MEF}_{25-75} \%$ predicted compared to baseline was $16.8 \%$ at the final visit $(\mathrm{p}=0.21)$.

Furthermore, $\mathrm{FEV}_{1}$ was determined by spirometry in $36 \mathrm{CF}$ patients 6 and 3 months before and 3 and 6 months after sequentially combined inhalational therapy. We found significant differences between $6(71.8 \pm 29.8 \%, p=0.024)$ and 3 months $(71.3 \pm 29.3 \%, p=$ $0.037)$ before the start compared to baseline $(68.8 \pm 26.3 \%)$ of the trial and not significant differences after 6 months $70.9 \pm 25.6 \%, \mathrm{p}=0.12$ ) of treatment. 


\section{Cellular Physiology Cell Physiol Biochem 2016;39:1141-1151

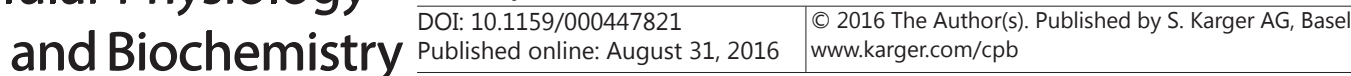 \\ Riethmüller et al.: Sequential Inhaled Antibiotics in CF}

Table 3. Lung function - time course and change from baseline to the end of the study (sub group). ${ }^{\text {a }}$ Change from baseline. FVC = forced vital capacity, $\mathrm{FEV}_{1}$ = forced expiratory volume in 1 second, $\mathrm{MEF}_{25} / \mathrm{MEF}_{25-75}$ $=$ maximal expiratory flow at $25 \%$ or between 25 and $75 \%$ of vital capacity. Means \pm SD are given

\begin{tabular}{lccccc}
\hline Characteristic & $\begin{array}{c}\text { Visit 1 } \\
\text { (Baseline) }\end{array}$ & $\begin{array}{c}\text { Visit 2 } \\
\text { (after 3 m) }\end{array}$ & $\begin{array}{c}\text { Visit 3 } \\
\text { (after 6 m) }\end{array}$ & p-value \\
\hline FVC [\% predicted] & $\mathrm{N}=29$ & $79.9 \pm 19.3$ & $82.5 \pm 32.3$ & $85.1 \pm 22.0$ & 0.035 \\
Absolute change & & & & $5.3 \pm 15.0$ & \\
\% (relative) change & & & & $6.2 \pm 18.0$ & \\
FEV [\% predicted] $^{\text {a }}$ & $\mathrm{N}=29$ & $69.4 \pm 24.2$ & $71.5 \pm 27.0$ & $74.4 \pm 24.4$ & 0.004 \\
Absolute change & & & & $4.9 \pm 9.6$ & \\
\% (relative) change & & & & $9.1 \pm 17.2$ & \\
MEF 25 [\% predicted] $^{\text {a }}$ & $\mathrm{N}=28$ & $32.4 \pm 26.7$ & $35.2 \pm 27.5$ & $31.6 \pm 25.6$ & 0.33 \\
Absolute change & & & & $1.6 \pm 19.1$ & \\
\% (relative) change & & & & $20.0 \pm 62.2$ & \\
$\mathrm{MEF}_{25-75}$ [\% predicted] & $\mathrm{N}=29$ & $47.4 \pm 32.3$ & $50.4 \pm 35.3$ & $46.0 \pm 32.3$ & 0.11 \\
Absolute change & & & & $4.2 \pm 17.8$ & \\
\% (relative) change & & & & $16.5 \pm 46.4$ & \\
\hline
\end{tabular}

Fig. 1. Sequential treatment with tobramycin and colistin increases lung function in 29 cystic fibrosis (CF) patients in a subgroup. Forced expiratory volume in $1 \mathrm{sec} \%$ predicted $\left(\mathrm{FEV}_{1}\right)$ was determined by spirometry 6 and 3 months before, at start, after 3 months and 6 months after sequentially combined inhalational therapy. Means \pm SD are given. $* \mathrm{p} \leq$ 0.05 ; $^{* *} \mathrm{p} \leq 0.005$, student's T-test.

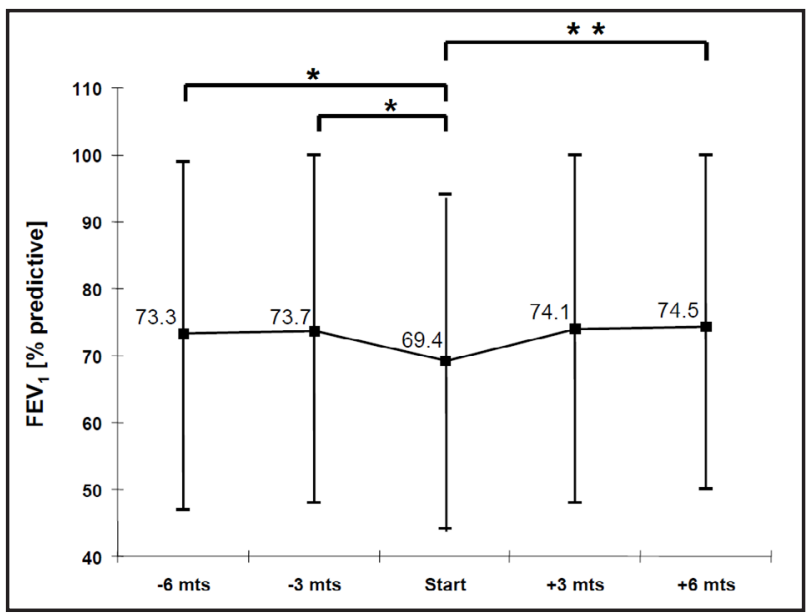

\section{Subgroup analyses}

29 patients were analyzed in the subgroup analyses (SG) and complete data are summarized in Table 3. Significant differences of 5.3 and 6.2 (absolute and relative, $\mathrm{p}=$ 0.036 ) in FVC \% predicted between baseline and final visit and $\mathrm{FEV}_{1} \%$ of predicted of 4.9 and $9.1 \%$ (absolute and relative, $p=0.004$ ) between baseline and final visit were observed. Furthermore the frequency of i.v. antibiotic therapy in the SG population had changed from a mean of $1.0 \pm 1.25$ at study start to $0.66 \pm 1.01$ at the final visit (difference of $34 \%, p=0.015$ ). Exacerbation rates similarly decreased from a mean of $1.1 \pm 1.72$ at study start to $0.83 \pm 0.97$ at the final visit (difference of $25 \%, \mathrm{p}=0.174$ ).

Furthermore, $\mathrm{FEV}_{1}$ was determined by spirometry in $29 \mathrm{CF}$ patients 6 and 3 months before and 3 and 6 months after sequentially combined inhalational therapy. We found significant differences $(p=0.02)$ between 6 and 3 months before the start of the trial and significant differences ( $p=0.0045)$ after 6 months of treatment (Fig. 1).

\section{Physician's Final Assessment of Efficacy}

At the final visit, the efficacy of the therapy was rated 'excellent' or 'good' by the physicians in $80.5 \%(\mathrm{~N}=33$ ) of patients (excellent: $31.7 \%, \mathrm{~N}=13$; good: $48.8 \%, \mathrm{~N}=20$ ). Efficacy was rated 'satisfactory' in $12.2 \%(\mathrm{~N}=5)$ and 'insufficient' in $2.4 \%(\mathrm{~N}=1)$ of patients. The final assessment of efficacy was missing for $4.9 \%(\mathrm{~N}=2)$ of patients. 


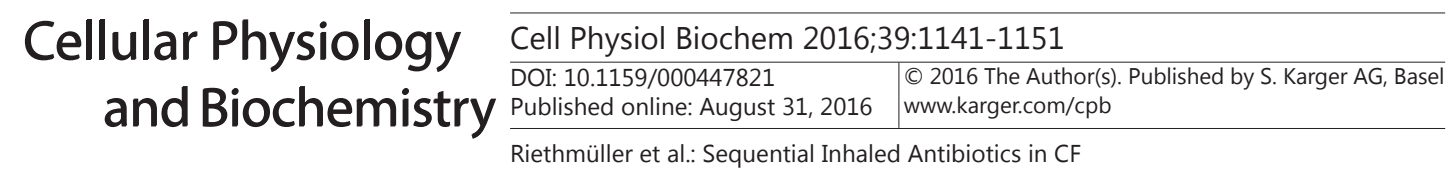

Table 4. Results of the modified CFQ-R (patients with complete data) in 32 patients

\begin{tabular}{|c|c|c|c|c|c|c|c|}
\hline \multirow{2}{*}{$\begin{array}{l}\text { Characteristic [n (\%)] } \\
\text { 1. Have your airways }\end{array}$} & \multirow[b]{2}{*}{ A great deal } & \multicolumn{2}{|c|}{$\begin{array}{c}\text { Visit } 1 \\
\text { (Baseline) }\end{array}$} & \multicolumn{2}{|c|}{$\begin{array}{c}\text { Visit } 2 \\
\text { (after } 3 \mathrm{~m} \text { ) }\end{array}$} & \multicolumn{2}{|c|}{$\begin{array}{c}\text { Visit } 3 \\
\text { (after } 6 \text { m) }\end{array}$} \\
\hline & & 6 & $(18.8)$ & 1 & $(3.1)$ & 0 & \\
\hline \multirow[t]{3}{*}{ been congested? } & Somewhat & 7 & $(21.9)$ & 11 & $(34.4)$ & 10 & (31.3) \\
\hline & A little & 15 & $(46.9)$ & 15 & $(46.9)$ & 13 & $(40.6)$ \\
\hline & Not at all & 5 & $(12.5)$ & 5 & $(15.6)$ & 9 & $(28.1)$ \\
\hline \multirow{4}{*}{$\begin{array}{l}\text { 2. Have you been } \\
\text { coughing during } \\
\text { the day? }\end{array}$} & A great deal & 5 & $(15.6)$ & 1 & (3.1) & 0 & \\
\hline & Somewhat & 11 & $(34.4)$ & 13 & $(40.6)$ & 11 & (34.4) \\
\hline & A little & 11 & $(34.4)$ & 13 & {$[40.6]$} & 15 & $(46.9)$ \\
\hline & Not at all & 4 & $(15.6)$ & 5 & [15.6] & 6 & $(18.8)$ \\
\hline \multirow{4}{*}{$\begin{array}{l}\text { 3. Have you had to } \\
\text { cough up mucus? }\end{array}$} & A great deal & 5 & $(15.6)$ & 0 & & 0 & \\
\hline & Somewhat & 8 & $(25.0)$ & 12 & $(37.5)$ & 9 & $(28.1)$ \\
\hline & A little & 13 & $(40.6)$ & 11 & $(34.4)$ & 16 & $(50.0)$ \\
\hline & Not at all & 6 & $(18.8)$ & 9 & $(28.1)$ & 7 & (21.9) \\
\hline \multirow{5}{*}{$\begin{array}{l}\text { 4. Has your mucus } \\
\text { mostly been: }\end{array}$} & Clear & 1 & $(4.8)$ & 3 & $(14.3)$ & 2 & $(9.5)$ \\
\hline & Light to yellow & 9 & $(42.9)$ & 11 & (52.4) & 12 & $(57.1)$ \\
\hline & Dark to greenish & 10 & $(47.6)$ & 6 & $(28.6)$ & 7 & $(33.3)$ \\
\hline & Bloody & 0 & & 0 & & 0 & \\
\hline & Don't know & 1 & $(4.8)$ & 1 & $(4.8)$ & 0 & \\
\hline \multirow{4}{*}{$\begin{array}{c}\text { 5. Have you been } \\
\text { wheezing? }\end{array}$} & Daily & 2 & $(6.3)$ & 1 & (3.1) & 0 & \\
\hline & Often & 3 & $(9.4)$ & 1 & (3.1) & 0 & \\
\hline & Sometimes & 15 & $(46.9)$ & 12 & $(37.5)$ & 11 & $(34.4)$ \\
\hline & Never & 12 & $(37.5)$ & 18 & $(56.3)$ & 21 & $(65.6)$ \\
\hline \multirow{4}{*}{$\begin{array}{l}\text { 6. Have you had trouble } \\
\text { breathing? }\end{array}$} & Daily & 5 & $(15.6)$ & 1 & (3.1) & 0 & \\
\hline & Often & 3 & (9.4) & 1 & (3.1) & 1 & (3.1) \\
\hline & Sometimes & 8 & $(25.0)$ & 11 & (34.4) & 12 & (37.5) \\
\hline & Never & 16 & $(50.0)$ & 19 & (59.4) & 19 & (59.4) \\
\hline \multirow{4}{*}{$\begin{array}{l}\text { 7. Have you woken up } \\
\text { during the night } \\
\text { because you were } \\
\text { coughing? }\end{array}$} & Daily & 3 & (9.4) & 2 & (6.3) & 0 & \\
\hline & Often & 4 & $(12.5)$ & 1 & (3.1) & 1 & (3.1) \\
\hline & Sometimes & 10 & $(31.3)$ & 9 & (28.1) & 9 & (28.1) \\
\hline & Never & 15 & $(46.9)$ & 20 & (62.5) & 22 & (68.8) \\
\hline
\end{tabular}

Final Assessment of Tolerability

The final assessment of tolerability (treatment regimen was not specified) was slightly more positive according to the physicians' assessment than according to the patients' assessment. The tolerability was rated 'excellent' or 'good' in $82.9 \%(\mathrm{~N}=34)$ of the study population by the physicians and in $68.3 \%(\mathrm{~N}=28)$ by the patients. Tolerability was rated 'satisfactory' in $9.8 \%(\mathrm{~N}=4)$ by the physicians and in $17.1 \%(\mathrm{~N}=7)$ by the patients. Tolerability was 'insufficient' in $2.4 \%(\mathrm{~N}=1)$, according to the physicians' as well as the patients' assessments. A final assessment of tolerability by the physician was missing for $4.9 \%(\mathrm{~N}=2)$ and by the patient for $12.2 \%(\mathrm{~N}=5)$ of all patients.

Patients' Assessment of Respiratory Symptoms (Modified CFQ-R)

Improvements in respiratory symptoms by means of the modified 7-item CFQ-R in the course of the study compared to baseline were indicated by the decrease in the number of patients with severe/frequent symptoms and the increase in the number of patients with mild/no symptoms (Table 4). The proportion of patients with severely ('a great deal') congested airways decreased, whereas the proportion of patients whose airways were not congested increased at the final visit. The proportion of patients with severe coughing during the day and patients who had to cough up mucus a great deal decreased, too. Throughout 


\section{Cellular Physiology Cell Physiol Biochem 2016;39:1141-1151 \\ \begin{tabular}{ll|l} 
DOI: 10.1159/000447821 & C 2016 The Author(s). Published by S. Karger AG, Basel \\
www.karger.com/cpb
\end{tabular} \\ Riethmüller et al.: Sequential Inhaled Antibiotics in CF}

the study, the proportion of patients who never had wheezing increased, the proportion of patients who never had trouble breathing increased and patients who never woke up during the night due to coughing increased.

Of the 32 patients with CFQ-R data available at all visits, 21 patients completed item 4 (colour of mucus) at all three visits. Most patients who did not answer this question at one or more visits had not had to cough up mucus. Based on the results of the 21 patients with complete data, there was a tendency towards a lighter/clearer color of the mucus throughout the course of the study.

\section{Discussion}

This multicentre, open-label, exploratory, non-interventional study was performed to collect clinical data on the therapy with inhaled tobramycin and/or colistin in CF patients with chronic $P$. aeruginosa infection of the lung under the conditions of daily practice. The tolerability of alternating therapy with inhaled antibiotics, the clinical effects of the treatment with inhaled tobramycin and/or colistin, and the treatment compliance were of interest. Our study is the first study to investigate the safety and efficacy of sequentially inhaled tobramycin and colistin treatment in CF patients [13]. We noted that the novel treatment regimen is safe and led to a significant increase in lung function in subgroup analyses.

Although the planned patient number of approximately 100 was not achieved due to difficulties in study centre recruitment, 41 patients was considered sufficient to draw some general conclusions from the descriptive analysis on clinical effects and tolerability of treatment with inhaled tobramycin and colistin. The majority of the patients had previously been treated with inhaled antibiotic monotherapy. At the start of the study, 93\% of the patients received sequential combination therapy with inhaled antibiotics. The most frequently named reason for starting sequential therapy was an aggravation of clinical symptoms. A decrease in $\mathrm{FEV}_{1}$ by more than $5 \%$ during the last year had been observed in almost half of the patients $(48.8 \%, \mathrm{~N}=20)$.

During the observation period, a total of 9 patients showed intolerance symptoms (including hoarseness/dysphonia, cough, and bronchial obstruction) after inhalation of tobramycin and/or colistin. Cough and hoarseness/dysphonia are adverse reactions which have commonly been observed in clinical studies with inhaled tobramycin and colistin [1417], but less frequent in our study; oropharyngeal pain has occasionally been observed. Post-marketing studies have shown that bronchoconstriction (bronchial obstruction) occurs rarely after inhalation of tobramycin [16]. However, in this study, there were 4 patients (9.8\%) with reported bronchial obstruction - all received sequential therapy with tobramycin and colistin. In 3 of the patients, bronchial obstruction was reported as adverse event (i.e. as related or probably related to tobramycin in 2 patients) and in one patient bronchial obstruction was reported as intolerance to inhaled colistin.

In clinical practice, several inhaled and systemic antibiotics are combined to treat CFassociated lung infections at this stage, but tolerability and efficacy of these combinations have not yet been systematically investigated $[10,11]$. To our knowledge this is the first study presenting data for a prospective sequential inhalation treatment. In vitro and in vivo combination treatment presented by our own group might not be as effective as it was presented first line [12]. Preliminary data of an ongoing cohort study (not published) combining tobramycin and colistin compared to colistin monotherapy reveal not the huge decrease of Pseudomonas colony forming units (cfu) usually seen in patients who are naïve to new formulations either to tobramycin or colistin $[14,17]$. Although not significant, the well-known increasing resistance against tobramycin was also shown in our study, but nevertheless we found an obviously beneficial clinical effect. However, further clinical trials with laboratory investigations such as molecular determination and counting of Pseudomonas strains or microbiome determination of pulmonary colonization should be done. Furthermore, susceptibility tests of combined antibiotics must be routinely implemented by microbiologists to verify synergistic effects in treatment of $P$. aeruginosa. 


\section{Cellular Physiology Cell Physiol Biochem 2016;39:1141-1151 \\ \begin{tabular}{ll|l} 
DOI: 10.1159/000447821 & $\begin{array}{l}\text { @ } 2016 \text { The Author(s). Published by S. Karger AG, Basel } \\
\text { www.karger.com/cpb }\end{array}$ \\
\hline
\end{tabular}}

During the observation period, improvements in lung function were observed. In this study a mean relative improvement in $\mathrm{FEV}_{1} \%$ predicted of $5.8 \%$ was noted in 38 patients. This is slightly lower than the $6.7 \%$ value observed by Hodson et al. after 4 weeks of treatment with inhaled tobramycin in a clinical study in patients with $\mathrm{CF}$ and $P$. aeruginosa infection $(\mathrm{N}=50$, median age: 20 years) [5]. The mean relative improvement in FVC \% predicted was $5.1 \%$. The inter-patient variability in the relative changes in the maximum expiratory flow variables was very high. The median relative improvement in $\mathrm{MEF}_{25-75}$ was $16.8 \%$ but with a broad range. There was a mean relative improvement in $\mathrm{MEF}_{25}$ of $21.3 \%$ again with a broad range of individual values (Table 3). Since in this study a sample size calculation was not done for the primary endpoint "lung function", no significance was expected for lung function parameters, Astonishingly the subgroup analysis showed a significant mean relative improvement in $\mathrm{FEV}_{1} \%$ predicted of $9.1 \%$ and mean relative improvement in FVC \% predicted of $6.2 \%$ in 29 patients (Table 3 and Fig. 1). These are remarkable results considering that patients were not naïve to either tobramycin or colistin.

According to the physicians' assessment at the final visit, a general clinical improvement was seen in 23 patients (56.1\%). In line with this, according to the physicians' assessment of respiratory symptoms, there were 22 patients with an improvement compared to baseline in at least one of the assessed respiratory symptoms (mucus production, coughing, and $\mathrm{FEV}_{1}$ ) at the final visit. Ten of these patients showed an improvement in all three assessed parameters. All three symptoms were improved with the same frequency, i.e. each symptom was improved in 16 patients (39.0\%). Improvements in respiratory symptoms in the course of the study were also seen according to the patients' assessment of respiratory symptoms by means of the modified CFQ-R.

The physicians' assessment of treatment efficacy at the final visit was positive in approximately $93 \%$ of the patients, i.e. efficacy was rated 'excellent' in 13 patients, 'good' in 20 patients, and 'satisfactory' in 5 patients.

At the end of the study, the patients' compliance to treatment was rated 'good' (>80\%) in $61.0 \%(\mathrm{~N}=25)$ of all patients. Compared to the compliance to the previous therapy, compliance had improved in $14.6 \%(\mathrm{~N}=6)$ of the patients. Increased compliance may have contributed to the improvements in lung function and respiratory symptoms. The final assessment of tolerability was slightly more positive according to the physicians' assessment than according to the patients' assessment. Possible reasons for this may be an underreporting of adverse events by the patients or that patients probably perceive their symptoms as being more severe than the physicians.

Since this trial was a non-interventional study the main limitation of the study is a missing control group and the small patient numbers. However, the observed period of six months before starting sequential therapy showed a significant decrease of lung function parameters in all patients, which might function as control data. Another limitation was that Pseudomonas species had not been described adequately in this study by molecular determination. Therefore, a post/pre comparison of different Pseudomonas lines could not be carried out satisfactorily. Moreover, the results need to be verified in a larger patient population.

Taken together, the results of this non-interventional, exploratory study in patients with $\mathrm{CF}$ and chronic $P$. aeruginosa infection of the lung indicated that, under the conditions of daily practice, treatment with inhaled antibiotics in sequential combination with tobramycin and colistin may have a beneficial effect on lung function and respiratory symptoms due to its ability to reduce exacerbation and intravenous treatment rates.

Sequential treatment with inhaled tobramycin and colistin was very well tolerated by most patients. However, physicians should be aware that bronchoconstriction may occur after inhalation of tobramycin or colistin.

\section{Acknowledgments}

We wish to thank the authors of Cystic Fibrosis Questionnaire Revised, German Version. 


\section{Cellular Physiology Cell Physiol Biochem 2016;39:1141-1151 \begin{tabular}{ll|l} 
DOI: 10.1159/000447821 & $\begin{array}{l}\text { O 2016 The Author(s). Published by S. Karger AG, Basel } \\
\text { www.karger.com/cpb }\end{array}$ \\
\hline
\end{tabular} \\ Riethmüller et al.: Sequential Inhaled Antibiotics in CF}

\section{Disclosure Statement}

No author has a conflict of interest in regards of drugs or assays discussed in this manuscript.

\section{References}

1 Rommens JM, Iannuzzi MC, Kerem B, Drumm ML, Melmer G, Dean M, Rozmahel R, Cole JL, Kennedy D, Hidaka N, et al.: Identification of the cystic fibrosis gene: chromosome walking and jumping. Science 1989;245:1059-1065.

2 Ratjen F, Döring G: Cystic Fibrosis. Lancet 2003;361:681-689.

3 Döring G, Flume P, Heijerman H, Elborn JS, for the Consensus Study Group: Treatment of Lung Infection in Patients with Cystic Fibrosis: Current and Future Strategies. J Cyst Fibros 2012;11:461-479.

4 Chmiel JF, Konstan MW, Elborn JS: Antibiotic and anti-inflammatory therapies for cystic fibrosis. Cold Spring HarbPerspect Med 2013;3:a009779.

5 Hodson ME, Gallagher CG, Govan JR: A randomised clinical trial of nebulised tobramycin or colistin in cystic fibrosis. Eur Respir J 2002;20:658-664.

6 Ramsey BW, Pepe MS, Quan JM, Otto KL, Montgomery B, Williams-Warren J, Vasiljev M, Borowitz D, Bowman M, Marshall BC, Marshall S, Smith AL: Intermittent administration of inhaled tobramycin in patients with cystic fibrosis. N Engl J Med 1999;340:23-30.

7 Høiby N, Ciofu 0, Bjarnsholt T: Pseudomonas aeruginosa biofilms in cystic fibrosis. Future Microbiol 2010;5:1663-1674.

8 Oliver A, Canton R, Campo P, Baquero F, Blazquez J: High frequency of hypermutable Pseudomonas aeruginosa in cystic fibrosis lung infection. Science 2000;288:1251-1254.

9 Levy J: Antibiotic activity in sputum. J Pediatr 1986;108:841-846.

10 Cox MJ, Allgaier M, Taylor B, Baek MS, Huang YJ, Daly RA, Karaoz U, Andersen GL, Brown R, Fujimura KE, Wu B, Tran D, Koff J, Kleinhenz ME, Nielson D, Brodie EL, Lynch SV: Airway Microbiota and Pathogen Abundance in Age-Stratified Cystic Fibrosis Patients. PLoS ONE 2010;5:e11044.

11 Döring G, Conway SP, Heijerman HGM, Hodson ME, Høiby N, Smyth A, Touw DJ: Antibiotic therapy against Pseudomonas aeruginosa in cystic fibrosis: a European consensus. Eur Respir J 2000;16:749-767.

12 Herrmann G, Yang L, Wu H, Song Z, Wang H, Høiby N, Riethmüller J, Ulrich M, Molin S, Döring G: Colistin/ tobramycin combinations are superior to monotherapy concerning the killing of biofilm P. aeruginosa. J Infect Dis 2010;202;1585-1592.

13 Berlana D, Llop JM, Manresa F, Jódar R: Outpatient Treatment of Pseudomonas aeruginosa Bronchial Colonization with Long-term Inhaled Colistin, Tobramycin, or Both in Adults without Cystic Fibrosis. Pharmacotherapy 2011;31:146-157.

14 Konstan MW, Geller DE, Minic' P, Brockhaus F, Angyalosi G: Tobramycin Inhalation Powder for P. aeruginosa Infection in Cystic Fibrosis: The EVOLVE Trial. Pediatr Pulmonol 2011;46:230-238.

15 Máiz L, Girón RM, Olveira C, Quintana E, Lamas A, Pastor D, Cantón R, Mensa J: Inhaled antibiotics for the treatment of chronic bronchopulmonary Pseudomonas aeruginosa infection in cystic fibrosis: systematic review of randomised controlled trials. Expert Opin Pharmacother 2013;14:1135-1349.

16 Ryan G, Jahnke N, Remmington T: Inhaled antibiotics for pulmonary exacerbations in cystic fibrosis. Cochrane Database Syst Rev 2012;12:CD008319.

17 Schuster A, Haliburn C, Döring G, Goldman MH; Freedom Study Group: Safety, efficacy and convenience of colistimethate sodium dry powder for inhalation (Colobreathe DPI) in patients with cystic fibrosis: a randomised study. Thorax 2013;68:344-350. 